\title{
Knowledge, Attitude, and Perception about Biostatistics among Health Researchers in Jeddah, Saudi Arabia
}

\author{
Prathibha Anand Nayak ${ }^{1}$, Esraa Hamdan Aljohani², Maram Abdulhabib Ali3 \\ Badriah Khalid Fatihi ${ }^{4}$, Norah Abdullah Alzubedy ${ }^{5}$, Ullal Anand Nayak ${ }^{6}$ \\ 1, 2,3,4,5 Department of Oral Basic \& Clinical Sciences, Ibn Sina National College for Medical Studies, Jeddah, Saudi Arabia, \\ ${ }^{6}$ Department of Preventive Dental Sciences, Ibn Sina National College for Medical Studies, Jeddah, Saudi Arabia
}

\section{ABSTRACT}

\section{BACKGROUND}

The principles and methods of biostatistics have gained importance in various fields including dentistry and medicine. The health researchers must have adequate knowledge and understanding of biostatistics to overcome the associated dilemmas in concluding the statistical data. The present study was planned to evaluate the knowledge, attitude, and perception of biostatistics among health researchers in Jeddah, Saudi Arabia.

\section{METHODS}

The present cross-sectional study was questionnaire based and was conducted among 251 health researchers in Saudi Arabia. A convenience method of sampling was followed during the 2 months study period from 15. 08. 2020 to 15.10. 2020. A pre-validated questionnaire was used that consisted of questions related to the knowledge, attitude and perception of biostatistics. A chi-square test was used to find the significance of study parameters and the level of significance chosen was $5 \%$.

\section{RESULTS}

Gender, nationality, or qualification of participants did not show any statistically significant differences with regards to their knowledge, attitude, or perception about biostatistics. The years of experience of the faculty showed statistically significant differences in their ability to interpret the results using statistical methods $[\mathrm{P}=$ $0.002]$, ability to choose a particular test to answer research question $[\mathrm{P}=0.024]$, ability to design their projects [P $=0.02]$, and forming opinions / making decisions in health care using statistical information $[\mathrm{P}=0.001]$. Nursing and dental faculty were able to design their research projects significantly better when compared to other groups. Faculty of Pharmacy, nursing, and dentistry more frequently used statistical information to form opinions or make decisions in health care when compared to those from the Medical program.

\section{CONCLUSIONS}

The study showed a medium level of knowledge as well as awareness about the importance of statistics in research and indicated a great motivation for further training with an emphasis on teaching and learning biostatistics during undergraduate / postgraduate education.

\section{KEY WORDS}

Biostatistics, Interpret Results, Health Researchers
Corresponding Author: Dr. Ullal Anand Nayak, Associate Professor, Department of Preventive Dental Sciences, Ibn Sina National College for Medical Studies, Jeddah, Saudi Arabia. E-mail: pediatricdentist4u@gmail.com

DOI: $10.14260 /$ jemds/2021/499

How to Cite This Article:

Nayak PA, Aljohani EH, Ali MA, et al. Knowledge, attitude, and perception about biostatistics among health researchers in Jeddah, Saudi Arabia. J Evolution Med Dent Sci 2021;10(31):2439-2445, DOI: 10.14260/jemds/2021/499

Submission 28-03-2021,

Peer Review 02-06-2021,

Acceptance 08-06-2021,

Published 02-08-2021.

Copyright (C) 2021 Prathibha Anand Nayak et al. This is an open access article distributed under Creative Commons Attribution License [Attribution 4.0 International (CC BY 4.0)] 


\section{BACKGROUND}

Biostatistics is a science consisting of statistical techniques and methods that has been used in the field of health sciences. The principles and methods of biostatistics have gained importance in various fields including dentistry and medicine. Health professionals and researchers are becoming more aware of their need for the understanding of biostatistics to formulate, analyze and interpret the data obtained. ${ }^{1}$ Today, evidence based dentistry (EBD), demands to make decisions scientific and evidence based thereby enabling to deliver best treatment and enhance its efficiency too. Hence it exerts a strong influence on the way the society values research. Thus, dental professionals should understand this to be proficient to evaluate the scientific literature and be able to collect available evidence of high standards, at the same time be able to reject evidences that are biased or confusing. ${ }^{2}$

Biostatistical flaws related to research studies are alarming, abundantly seen in medical and / dental literature, and can lead to bias of study results. ${ }^{2}$ It is estimated that the reported error rates of various statistical analyses seen in medical journal articles range between $27 \%$ and $90 \%{ }^{3}$ The most serious errors frequently reported were determination of the study type, sample size and confidence interval, selection of tests (parametric), frequency measure analysis, bias related to selection and the choice of confusion factors. ${ }^{4}$ It is astonishing from the findings of a systematic review that of manuscripts published in 34 reputed international journals bearing high impact factor, no adjustment for the confounding factors was provided for in $10 \%$ of them. ${ }^{5}$

Nowadays reviewing journal articles has become a routine for academicians in medical field and this may have an influence on delivery of patient care. ${ }^{6}$ These educational activities intend to train physicians with skills to apply their knowledge about study design and statistical methods for effective evaluation of clinical studies. ${ }^{7}$ Hence, the present study was planned to evaluate the knowledge, attitude, and perception of biostatistics among the health researchers in Jeddah, Saudi Arabia.

\section{METHODS}

The present cross-sectional questionnaire-based study was conducted among the health researchers in Jeddah, Saudi Arabia after obtaining the institutional ethical committee approval. A convenience method of sampling was followed during the 2 months study period from 15. 08. 2020 to 15.10 . 2020. A pre-validated questionnaire from the published study of Sujata $(2018)^{8}$ was selected and minor modifications were made after consultation with three subject experts. A closedended multiple choice questionnaire was finalized that consisted of 20 questions about their knowledge, 7 - attitude 7 - perception and 6 about biostatistics. The questionnaire was emailed to participants with a note that their responses to the questionnaire would be considered as their willingness to participate in the study.

The participant's demographic data regarding their gender, department, and the academic position was collected.
The questionnaire included questions related to the knowledge, attitude, and perception of biostatistics. The participants were assured that their responses would not be disclosed in public to maintain confidentiality. The response options were graded on 5 point Likert scale ranging from -2 : Strongly disagree to 2: Strongly agree

\section{Statistical Analysis}

The data received from the duly filled questionnaires were subjected to statistical analysis. Descriptive and inferential statistical analyses were carried out. SPSS 22 Version [IBM, Chicago, USA] was used for the analysis of the data. The level of significance was set at $5 \%$. A chi-square test was used to find the significance of study parameters.

\section{RESULTS}

Table 1 shows the demographic data of 251 respondents who had filled all the questions of the questionnaire. Table 2 shows the responses of the participants to the questions related to biostatistics. Table 3 shows the perception of the participants regarding interpreting the results of the statistical method used in research. There was a statistically significant difference observed among variables such as faculty of different programs $[\mathrm{P}=0.003]$, years of their teaching experience $[\mathrm{P}=0.002]$, and career focus $[\mathrm{P}=0.009] .32 .2 \%$ of faculty members of the medical program were of the opinion that they could not interpret the results of a statistical method in contrast to Nursing [25.7\%], Dentistry [17.5 \%], and Pharmacy [16.5\%] programs. In terms of years of experience, faculty with experience of 11 - 15 years, 16 - 20 years, and more than 20 years could appropriately interpret their results in contrast to 6 - 10 years and 0 - 5 years. $57.4 \%$ of participants who were in academics believed that they could appropriately interpret their results when compared to non academic [36.1 $\%]$ and this difference was statistically significant $[\mathrm{P}=0.009]$.

\begin{tabular}{|ccc|}
\hline Demographic Characteristics & Number (\%) \\
Gender & Male & $114(45.4 \%)$ \\
& Female & $137(54.6 \%)$ \\
& Medical & $90(35.9 \%)$ \\
Faculty member & Dental & $86(34.3 \%)$ \\
& Pharmacy & $40(15.9 \%)$ \\
& Nursing & $35(13.9 \%)$ \\
Nationality & Saudi & $153(61 \%)$ \\
& Non - Saudi & $98(39 \%)$ \\
& $0-5$ & $98(39 \%)$ \\
Years of experience & $6-10$ & $64(25.5 \%)$ \\
& $11-15$ & $31(12.4 \%)$ \\
& $16-20$ & $22(8.8 \%)$ \\
& $>20$ & $36(14.3 \%)$ \\
Qualification & Board & $110(43.8 \%)$ \\
& Masters & $94(37.5 \%)$ \\
& PhD & $47(18.7 \%)$ \\
Career focus & Clinical - Academic & $82(32.7 \%)$ \\
& Clinical - Non & $169(67.3 \%)$ \\
\hline \multicolumn{2}{c}{ Table 1 Demographic Data of Respondents } \\
\hline \multicolumn{2}{c}{ academic } \\
\hline
\end{tabular}

Table 4 shows the ability of the participants to identify an appropriate statistical test to answer a research question. There were no statistically significant differences in this regard among variables such as gender $[\mathrm{P}=0.601]$, type of program $[\mathrm{P}=0.416]$, nationality $[\mathrm{P}=0.130]$, qualification $[\mathrm{P}=$ 0.872], and career focus $[\mathrm{P}=0.391]$. However, concerning the 
years of experience, faculty with experience of 20 years and more could identify appropriate statistical tests required to answer a research question better in contrast to other groups $[\mathrm{P}=0.024]$. Table 5 shows the ability of the participants to design their projects. There were no statistically significant differences in this regard among variables such as gender $[\mathrm{P}=$ 0.672], nationality [P $=0.672]$, and qualification [ $\mathrm{P}=0.307]$. However, there were statistically significant differences observed among variables such as faculty of different programs $[\mathrm{P}=0.033]$, years of their teaching experience $[\mathrm{P}=$ $0.02]$, and career focus $[P=0.003]$. Faculty members of Pharmacy [42.5 \%], medical [37.5\%], Nursing [25.7\%] programs were of the opinion that they could not design their projects in contrast to those in the Dentistry program [19.8\%] and this difference was statistically significant $[\mathrm{P}=0.033]$.

In terms of years of experience, faculty with experience of 11 - 15 years, 16 - 20 years, and more than 20 years could design their projects significantly better in contrast to those with 6 - 10 years and $0-5$ years' experience [P $=0.02] .56 .1 \%$ of faculties who were Academic could design their projects significantly better when compared to those who were non academic [36.7\%] [P=0.003].

Table 6 shows use of statistical information to form opinions or make decisions in health care. There were no statistically significant differences in this regard among variables such as gender $[\mathrm{P}=0.108]$, nationality $[\mathrm{P}=0.285]$, qualification $[\mathrm{P}=0.241]$ and career focus $[\mathrm{P}=0.187]$. However, there were statistically significant differences observed among variables such as faculty of different programs $[\mathrm{P}<0.001]$ and years of their teaching experience $[\mathrm{P}<0.001]$. Faculty members of Nursing [48.5 \%] Pharmacy [42.5\%], Dental [40.7 $\%$ ] programs used statistical information to form opinions or make decisions in health care in contrast to those in Medical program [38.9\%], and this difference was statistically significant $[\mathrm{P}<0.001]$. In terms of years of experience, faculty with experience of 6 - 10 years and those $>20$ years often used statistical information to form opinions or make decisions in health in contrast to those with 0 - 5 years, 11 - 15 years, and 16 - 20 year groups.

\begin{tabular}{|c|c|c|c|c|c|c|}
\hline & Questions & $\begin{array}{c}\text { Strongly } \\
\text { Agree }\end{array}$ & Agree & Neutral & Disagree & $\begin{array}{l}\text { Strongly } \\
\text { Disagree }\end{array}$ \\
\hline \multirow{7}{*}{$\begin{array}{l}\text { Knowledge and Understanding of } \\
\text { Biostatistics }\end{array}$} & I can understand most of the statistical terms found in journal articles & $26(10.4 \%)$ & $101(40.2 \%)$ & $72(28.7 \%)$ & $27(10.8 \%)$ & $25(10 \%)$ \\
\hline & $\begin{array}{l}\text { I often use statistical information to form opinions or make decisions } \\
\text { in health care }\end{array}$ & $33(13.1 \%)$ & $75(29.9 \%)$ & $85(33.9 \%)$ & $30(12 \%)$ & $28(11.2 \%)$ \\
\hline & $\begin{array}{l}\text { To understand medical literature better, I believe that it is necessary } \\
\text { to know about statistics }\end{array}$ & $50(19.9 \%)$ & $97(38.6 \%)$ & $55(21.9 \%)$ & $25(10 \%)$ & $23(9.2 \%)$ \\
\hline & I can appropriately interpret $\mathrm{P}$ value of results of a study & $26(10.4 \%)$ & $84(33.5 \%)$ & $75(29.9 \%)$ & $41(16.3 \%)$ & $25(10 \%)$ \\
\hline & $\begin{array}{l}\text { I can appropriately interpret the results of a statistical method used in } \\
\text { research }\end{array}$ & $32(12.7 \%)$ & $76(30.3 \%)$ & $81(32.3 \%)$ & $38(15.1 \%)$ & $24(9.6 \%)$ \\
\hline & $\begin{array}{l}\text { I can identify the appropriate statistical test used to answer a } \\
\text { research question }\end{array}$ & $23(9.2 \%)$ & $68(27.1 \%)$ & $80(31.9 \%)$ & $54(21.5 \%)$ & $26(10.4 \%)$ \\
\hline & I can identify the factors that influence the power of the study & $34(13.5 \%)$ & $89(35.5 \%)$ & $63(25.1 \%)$ & $44(17.5 \%)$ & $21(8.4 \%)$ \\
\hline \multirow{7}{*}{$\begin{array}{l}\text { Attitude and training related to } \\
\text { biostatistics }\end{array}$} & A good researcher must have undergone basic training in statistics & $84(33.5 \%)$ & $78(31.1 \%)$ & $42(16.7 \%)$ & $28(11.2 \%)$ & $19(7.6 \%)$ \\
\hline & $\begin{array}{l}\text { Biostatistics course was taught effectively at undergraduate or } \\
\text { postgraduate level }\end{array}$ & $32(12.7 \%)$ & $83(33.1 \%)$ & $57(22.7 \%)$ & $55(21.9 \%)$ & $24(9.6 \%)$ \\
\hline & Statistics is best left to experts & $37(14$ & $76(30$. & 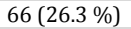 & 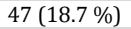 & $25(10 \%)$ \\
\hline & Statistics is too complicated for me & $28(11.2 \%)$ & $79(31.5 \%)$ & $65(25.9 \%)$ & $54(21.5 \%)$ & $25(10 \%)$ \\
\hline & I am able to design my ow & & & & & $26(10.4 \%)$ \\
\hline & I have difficulty in analyzing the statistics of my article & $27(10.8 \%)$ & $75(29.9 \%)$ & $75(29.9 \%)$ & $50(19.9 \%)$ & $24(9.6 \%)$ \\
\hline & Biostatistician has a high status in the field of medical research & $50(19.9 \%)$ & $102(40.6 \%)$ & $62(24.7 \%)$ & $23(9.2 \%)$ & $14(5.6 \%)$ \\
\hline \multirow{6}{*}{$\begin{array}{l}\text { Perceptions Regarding Importance } \\
\text { of Biostatistics in Medical Science }\end{array}$} & $\begin{array}{l}\text { Knowledge of biostatistics is necessary when evaluating medical } \\
\text { literature }\end{array}$ & $61(24.3 \%)$ & $92(36.7 \%)$ & $61(24.3 \%)$ & $21(8.4 \%)$ & $16(6.4 \%)$ \\
\hline & Biostatistics is more difficult than other subjects in medical training & $36(14.3 \%)$ & $77(30.7 \%)$ & $85(33.9 \%)$ & $37(14.7 \%)$ & $16(6.4 \%)$ \\
\hline & $\begin{array}{l}\text { Biostatistician would be more helpful if they understood medical } \\
\text { sciences too }\end{array}$ & 65 & 104 & ) & ) & 12 \\
\hline & Biostatisticians are not necessary for most of the research & $13(5.2 \%)$ & $49(19.5 \%)$ & $49(19.5 \%)$ & $86(34.3 \%)$ & $54(21.5 \%)$ \\
\hline & Biostatistics is a necessary skill for a clinician involved in research & $62(24.7 \%)$ & $98(39 \%)$ & $47(18.7 \%)$ & $29(11.6 \%)$ & $15(6 \%)$ \\
\hline & Biostatistics is an important part of evidence based dentistry & $82(32.7 \%)$ & $97(38.6 \%)$ & $36(14.3 \%)$ & $17(6.8 \%)$ & $19(7.6 \%)$ \\
\hline
\end{tabular}

\begin{tabular}{|c|c|c|c|c|c|c|c|c|}
\hline \multicolumn{9}{|c|}{ I can Appropriately Interpret the Results of a Statistical Method Used in Research } \\
\hline & & Strongly Agree & Agree & Neutral & Disagree & $\begin{array}{l}\text { Strongly } \\
\text { Disagree }\end{array}$ & Chi Square & P Value \\
\hline \multirow{2}{*}{ Gender } & Male & $16(14 \%)$ & $32(28.1 \%)$ & $35(30.7 \%)$ & $19(16.7 \%)$ & $12(10.5 \%)$ & \multirow{3}{*}{1.292} & \multirow{3}{*}{0.863} \\
\hline & Female & $16(11.7 \%)$ & $44(32.1 \%)$ & $46(33.6 \%)$ & $19(13.9 \%)$ & $12(8.8 \%)$ & & \\
\hline \multirow{4}{*}{ Faculty member } & Dental & 7 (8.1\%) & $35(40.7 \%)$ & 29 (33.7\%) & $9(10.5 \%)$ & $6(7 \%)$ & & \\
\hline & Medical & $10(11.1 \%)$ & 19 (21.1\%) & $32(35.6 \%)$ & $17(18.9 \%)$ & $12(13.3 \%)$ & \multirow{3}{*}{29.748} & \multirow{3}{*}{0.003} \\
\hline & Nursing & $2(5.7 \%)$ & $14(40 \%)$ & $10(28.6 \%)$ & $7(20 \%)$ & $2(5.7 \%)$ & & \\
\hline & Pharmacy & $13(32.5 \%)$ & $8(20 \%)$ & $10(25 \%)$ & $5(12.5 \%)$ & $4(10 \%)$ & & \\
\hline \multirow{2}{*}{ Nationality } & Saudi & 15 (9.8\%) & $45(29.4 \%)$ & $56(36.6 \%)$ & $20(13.1 \%)$ & 17 (11.1\%) & \multirow{2}{*}{7.131} & \multirow{2}{*}{0.129} \\
\hline & Non Saudi & $17(17.3 \%)$ & $31(31.6 \%)$ & $25(25.5 \%)$ & $18(18.4 \%)$ & $7(7.1 \%)$ & & \\
\hline \multirow{5}{*}{ Years of experience } & $0-5$ & $7(7.1 \%)$ & $24(24.5 \%)$ & $42(42.9 \%)$ & $15(15.3 \%)$ & $10(10.2 \%)$ & \multirow{5}{*}{36.613} & \multirow{5}{*}{0.002} \\
\hline & $6-10$ & $15(23.4 \%)$ & $21(32.8 \%)$ & $13(20.3 \%)$ & $12(18.8 \%)$ & $3(4.7 \%)$ & & \\
\hline & $11-15$ & $2(6.5 \%)$ & $10(32.3 \%)$ & $12(38.7 \%)$ & $4(12.9 \%)$ & $3(9.7 \%)$ & & \\
\hline & $16-20$ & $2(9.1 \%)$ & $7(31.8 \%)$ & $7(31.8 \%)$ & $6(27.3 \%)$ & 0 & & \\
\hline & $>20$ & $6(16.7 \%)$ & $14(38.9 \%)$ & $7(19.4 \%)$ & $1(2.8 \%)$ & $8(22.2 \%)$ & & \\
\hline \multirow{3}{*}{ Qualification } & Board & $12(10.9 \%)$ & $35(31.8 \%)$ & $32(29.1 \%)$ & $19(17.3 \%)$ & $12(10.9 \%)$ & \multirow{3}{*}{6.772} & \multirow{3}{*}{0.561} \\
\hline & Masters & $15(16 \%)$ & $24(25.5 \%)$ & $34(36.2 \%)$ & $15(16 \%)$ & $6(6.4 \%)$ & & \\
\hline & $\mathrm{PhD}$ & $5(10.6 \%)$ & $17(36.2 \%)$ & $15(31.9 \%)$ & $4(8.5 \%)$ & $6(12.8 \%)$ & & \\
\hline \multirow[b]{2}{*}{ Career focus } & $\begin{array}{l}\text { Clinical - } \\
\text { Academic }\end{array}$ & $13(15.9 \%)$ & $34(41.5 \%)$ & $20(24.4 \%)$ & $6(7.3 \%)$ & $9(11 \%)$ & \multirow[b]{2}{*}{13.473} & \multirow[b]{2}{*}{0.009} \\
\hline & $\begin{array}{l}\text { Clinical - Non } \\
\text { academic }\end{array}$ & $19(11.2 \%)$ & $42(24.9 \%)$ & $61(36.1 \%)$ & $32(18.9 \%)$ & $15(8.9 \%)$ & & \\
\hline \multicolumn{9}{|c|}{$P$ value $<0.05$ is significant } \\
\hline & ble 3. Perc & of the Parti & Regarding & preting the & of Statis & hod Usec & arch & \\
\hline
\end{tabular}




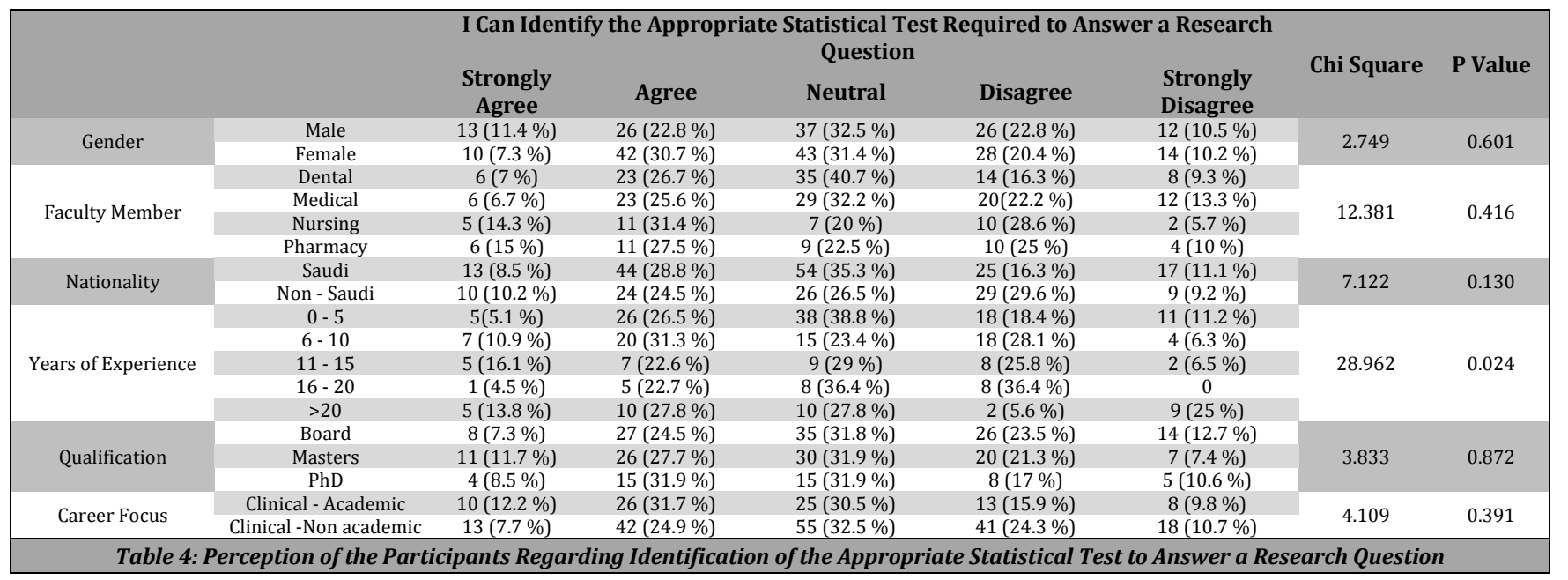

\begin{tabular}{|c|c|c|c|c|c|c|c|c|}
\hline & & \multicolumn{5}{|c|}{ I am Able to Design My Own Research Projects } & \multirow[b]{2}{*}{ Chi Square } & \multirow[b]{2}{*}{ P Value } \\
\hline & & Strongly Agree & Agree & Neutral & Disagree & $\begin{array}{l}\text { Strongly } \\
\text { Disagree }\end{array}$ & & \\
\hline \multirow{2}{*}{ Gender } & Male & $12(10.5 \%)$ & $35(30.7 \%)$ & $27(23.7 \%)$ & $27(23.7 \%)$ & $13(11.4 \%)$ & \multirow{2}{*}{2.347} & \multirow{2}{*}{0.672} \\
\hline & Female & 13 (9.5\%) & $48(35 \%)$ & $39(28.5 \%)$ & $24(17.5 \%)$ & $13(9.5 \%)$ & & \\
\hline \multirow{4}{*}{ Faculty member } & Dental & $12(14 \%)$ & $33(38.4 \%)$ & $24(27.9 \%)$ & $12(14 \%)$ & $5(5.8 \%)$ & \multirow{4}{*}{22.449} & \multirow{4}{*}{0.033} \\
\hline & Medical & $4(4.4 \%)$ & $24(26.7 \%)$ & $28(31.1 \%)$ & $22(24.2 \%)$ & 12 (13.3 \%) & & \\
\hline & Nursing & $2(5.7 \%)$ & $17(48.6 \%)$ & $7(20 \%)$ & $6(17.1 \%)$ & $3(8.6 \%)$ & & \\
\hline & Pharmacy & $7(17.5 \%)$ & $9(22.5 \%)$ & $7(17.5 \%)$ & $11(27.5 \%)$ & $5(15 \%)$ & & \\
\hline Nationality & Saudi & $17(11.1 \%)$ & $48(31.4 \%)$ & $43(28.1 \%)$ & $28(18.3 \%)$ & $117(11.1 \%)$ & 2.350 & 0.672 \\
\hline \multirow{5}{*}{ Years of experience } & $0-5$ & $8(8.2 \%)$ & $24(24.5 \%)$ & $36(36.7 \%)$ & $18(18.4 \%)$ & $12(12.2 \%)$ & \multirow{5}{*}{26.622} & \multirow{5}{*}{0.020} \\
\hline & $6-10$ & $10(15.6 \%)$ & $19(29.7 \%)$ & $15(23.4 \%)$ & $19(29.7 \%)$ & $1(1.6 \%)$ & & \\
\hline & $11-15$ & $3(9.7 \%)$ & $14(45.2 \%)$ & $5(16.1 \%)$ & $5(16.1 \%)$ & $4(12.9 \%)$ & & \\
\hline & $16-20$ & $1(4.5 \%)$ & $10(45.5 \%)$ & $4(18.2 \%)$ & $5(22.7 \%)$ & $2(9.1 \%)$ & & \\
\hline & $>20$ & $3(8.3 \%)$ & $16(44.4 \%)$ & $6(16.7 \%)$ & $4(11.1 \%)$ & $7(19.4 \%)$ & & \\
\hline \multirow{3}{*}{ Qualification } & Board & $10(9.1 \%)$ & $34(30.9 \%)$ & $28(25.5 \%)$ & $24(21.8 \%)$ & $14(12.7 \%)$ & \multirow{3}{*}{9.434} & \multirow{3}{*}{0.307} \\
\hline & Masters & $14(14.9 \%)$ & $31(33 \%)$ & $22(23.4 \%)$ & $20(21.3 \%)$ & $7(7.4 \%)$ & & \\
\hline & $\mathrm{PhD}$ & $1(2.1 \%)$ & $18(38.3 \%)$ & $16(34 \%)$ & $7(14.9 \%)$ & $5(10.6 \%)$ & & \\
\hline \multirow[b]{2}{*}{ Career focus } & Clinical - Academic & $14(17.1 \%)$ & $32(39 \%)$ & $20(24.4 \%)$ & $7(8.5 \%)$ & $9(11 \%)$ & \multirow[b]{2}{*}{16.027} & \multirow[b]{2}{*}{0.003} \\
\hline & $\begin{array}{c}\text { Clinical - } \\
\text { Non academic }\end{array}$ & $11(6.5 \%)$ & $51(30.2 \%)$ & $46(27.2 \%)$ & $44(26 \%)$ & 17 (10.1\%) & & \\
\hline & Table 5 Per & $n$ of the $P a$ & s Regard & eir Ability & Their & earch Proj & & \\
\hline
\end{tabular}

\begin{tabular}{|c|c|c|c|c|c|c|c|c|}
\hline & & \multicolumn{5}{|c|}{ I Often Use Statistical Information to Form Opinions or Make Decisions in Health Care } & \multirow[b]{2}{*}{ Chi Square } & \multirow{2}{*}{ P Value } \\
\hline & & Strongly Agree & Agree & Neutral & Disagree & Strongly Disagree & & \\
\hline \multirow{2}{*}{ Gender } & Male & $19(16.7 \%)$ & $37(32.5 \%)$ & $29(25.4 \%)$ & $14(12.3 \%)$ & $15(13.2 \%)$ & \multirow[b]{2}{*}{7.580} & \multirow{2}{*}{0.108} \\
\hline & Female & $14(10.2 \%)$ & $38(27.7 \%)$ & $56(40.9 \%)$ & $16(11.7 \%)$ & $13(9.5 \%)$ & & \\
\hline \multirow{4}{*}{ Faculty member } & Dental & $7(8.1 \%)$ & $28(32.6 \%)$ & $39(45.3 \%)$ & $6(7 \%)$ & $6(7 \%)$ & \multirow{4}{*}{39.278} & \multirow{4}{*}{0.000} \\
\hline & Medical & $7(7.8 \%)$ & $28(31.1 \%)$ & $31(34.4 \%)$ & $12(13.3 \%)$ & $12(13.3 \%)$ & & \\
\hline & Nursing & $4(11.4 \%)$ & $13(37.1 \%)$ & $7(20 \%)$ & $7(20 \%)$ & $4(11.4 \%)$ & & \\
\hline & Pharmacy & $15(37.5 \%)$ & $6(15 \%)$ & $8(20 \%)$ & $5(12.5 \%)$ & $6(15 \%)$ & & \\
\hline \multirow{2}{*}{ Nationality } & Saudi & $19(12.4 \%)$ & $43(28.1 \%)$ & $53(34.6 \%)$ & $16(10.5 \%)$ & $22(14.4 \%)$ & \multirow{2}{*}{5.025} & \multirow{2}{*}{0.285} \\
\hline & Non - Saudi & $14(14.3 \%)$ & $32(32.7 \%)$ & $32(32.7 \%)$ & $14(14.3 \%)$ & $6(6.1 \%)$ & & \\
\hline \multirow{5}{*}{ Years of experience } & $0-5$ & $5(5.1 \%)$ & $28(28.6 \%)$ & $45(45.9 \%)$ & $10(10.2 \%)$ & $10(10.2 \%)$ & \multirow{5}{*}{42.692} & \multirow{5}{*}{0.000} \\
\hline & $6-10$ & $17(26.6 \%)$ & $18(28.1 \%)$ & $17(26.6 \%)$ & $5(7.8 \%)$ & $7(10.9 \%)$ & & \\
\hline & $11-15$ & $4(12.9 \%)$ & $8(25.8 \%)$ & $6(19.4 \%)$ & $9(29 \%)$ & $4(12.9 \%)$ & & \\
\hline & $16-20$ & $3(13.6 \%)$ & $8(36.4 \%)$ & $3(13.6 \%)$ & $6(27.3 \%)$ & $2(9.1 \%)$ & & \\
\hline & $>20$ & $4(11.1 \%)$ & $13(36.1 \%)$ & $14(38.9 \%)$ & 0 & $5(13.9 \%)$ & & \\
\hline \multirow{3}{*}{ Qualification } & Board & $11(10 \%)$ & $29(26.4 \%)$ & $40(36.4 \%)$ & $12(10.9 \%)$ & $18(16.4 \%)$ & \multirow{3}{*}{10.359} & \multirow{3}{*}{0.241} \\
\hline & Masters & $17(18.1 \%)$ & $31(33 \%)$ & $28(29.8 \%)$ & $13(13.8 \%)$ & $5(5.3 \%)$ & & \\
\hline & PhD & $5(10.6 \%)$ & $15(31.9 \%)$ & $17(36.2 \%)$ & $5(10.6 \%)$ & $5(10.6 \%)$ & & \\
\hline \multirow[b]{2}{*}{ Career focus } & Clinical - Academic & $15(18.3 \%)$ & $29(35.3 \%)$ & $22(26.8 \%)$ & $8(9.8 \%)$ & $8(9.8 \%)$ & \multirow[b]{2}{*}{6.164} & \multirow[b]{2}{*}{0.187} \\
\hline & $\begin{array}{l}\text { Clinical -Non } \\
\text { academic }\end{array}$ & $18(10.7 \%)$ & $46(27.2 \%)$ & $63(37.3 \%)$ & $22(13 \%)$ & $20(11.8 \%)$ & & \\
\hline \multicolumn{9}{|c|}{$P$ value $<0.05$ is significant } \\
\hline $\overrightarrow{b l}$ & ctices of the & icipants Rega & Ise of Stat & Informat & m Opin & Make Decis & Hed & \\
\hline
\end{tabular}

\section{DISCUSSION}

The present study showed that $43.3 \%$ of respondents were confident enough in designing their research projects. The statistical knowledge of doctors about biostatistics was unsatisfactory as reported by Altman et al. ${ }^{9}$ In the present study, there was no statistically significant difference related to gender and the application of statistical tests. Whereas in a study, men have been found to perform better than women concerning math performance ${ }^{10}$ which is in contrast to the results of our study. However, according to another study, females were more confident about conducting their statistical analysis. A meta-analysis of recently conducted studies regarding gender and mathematics performance reported that males and females were at par. ${ }^{11}$

The responses to the questionnaire were also influenced by the academic position and career focus of the respondents.

The confidence of application of statistical tests was much greater among the respondents whose career focus was research or clinical along with academics than those 
respondents whose focus was clinical but non academic. The former group was more frequently interacting with the students about biostatistics during research and academic sessions and hence were more updated.

The present study suggests that approximately half the respondents thought that they could understand the statistical terms that were commonly used in scientific articles and also identified the factors that influenced the power of the study. Less than $50 \%$ of respondents could confidently interpret the $\mathrm{P}$ - value and results of the study. However, approximately 60 $\%$ of them believed that good basic training in statistics during undergraduate training was vital and this knowledge would help them to evaluate the medical literature better. This percentage was lower when compared to the study done by Windish in $2007^{12}$ who reported that $94 \%$ of the respondents believed proper understanding of biostatistics was necessary to evaluate the research design and interpret the results appropriately. $45 \%$ of the participants believed that biostatistics was more difficult than other subjects in medical training which was similar to the findings of certain recent studies. ${ }^{13,14}$ Majority of respondents in the present study agreed that knowing medical sciences would benefit biostatistician too.

Most of the training in biostatistics usually is completed during undergraduate studies and is generally never reinforced in postgraduate programs. The lack of knowledge of biostatistics may hence reflect inadequate and inefficient training. A recent study revealed that the biostatistics knowledge scores were better among the residents when compared to junior doctors and professors irrespective of gender or previous biostatistics training. ${ }^{15}$ This lower perception of knowledge among faculty indicates a need for further motivation for training in biostatistics. This further suggests the need for integrating biostatistics as a subject in the medical / dental curriculum. Incorporating it into the medical curriculum and evidence based medical practice would pave new ways into the research field.

Emphasis should be given on biostatistics training during undergraduate / postgraduate programs so that the faculty / practitioners can critically appraise the research question, can design and analyze their study as well as correctly interpret the results.

A study conducted by Gezmu et al. highlighted that the Sub - Saharan African Universities do not emphasize biostatistics training due to limited resources. ${ }^{16}$ The poor interest and knowledge of biostatistics among the practitioners in the region indicates insufficient training on research methodologies and statistical software. Although the majority of participants mentioned taking up of biostatistics as a part of community medicine, emphasis on the subject was never given during the educational tenure.

Most of the researchers are not linked with training on biostatistics and so are not aware of the importance of biostatistics. A study conducted in Jeddah assessed the satisfaction of 80 family physicians during their training program and reported that the least important area of competence during their community medicine course was biostatistics. In the same study, the physicians were moderately trained in biostatistics. ${ }^{17}$

A lack of clear biostatistics knowledge and a negative attitude towards its application in their regular practice was observed in another study by Javali and Sunkad. ${ }^{18}$ Further, Rashid and Subramaniam ${ }^{19}$ in their study found that most of the participants were hesitant to attend any additional short courses on biostatistics as they found the training of it to be difficult and time consuming. Their study reported $54.64 \%$ of participants to have a negative attitude towards learning related to Biostatistics.

Presently, many medical schools provide formal training on basic biostatistics and their use in the medical literature.7,19 These educational activities are designed to train the practitioners / academicians with skills to apply their knowledge about study design and statistical analysis of clinical studies.

The findings of the study are in line with a recent study on healthcare professionals in India. ${ }^{18}$ A cross-sectional multi country survey on 531 clinicians reported that the participants poorly understood the study results in terms of the standardized mean difference. ${ }^{20}$ Moreover, the knowledge of statistics was perceived to be the least useful in the study. The same study further recommended clinicians to develop newer tools to understand and interpret its results.

In contrast to the above studies, numerous studies also reported that healthcare professionals have the required knowledge of biostatistics. A study involving 162 resident physicians revealed that more than half of the participants had good knowledge about statistics. ${ }^{21}$ Further, the participants exhibited knowledge and were able to analyze or interpret the findings of their research. The prior training in EBM led to higher knowledge scores among the residents. Similarly, another study performed on nurses and nurse practitioners in Northern Virginia, United States revealed a very positive attitude toward statistics at the beginning of training in biostatistics which improved further along with better statistical proficiency at the end of training. ${ }^{22}$

Furthermore, regular reading, publishing research articles / papers have resulted in better knowledge of biostatistics. ${ }^{23}$ Thus continuous professional education in research is necessary to remain updated. This further ensures high quality indexed publications by the health professionals in the long run.

Physicians most often find the subject very difficult as compared to other biomedical subjects despite knowing the importance of statistical analysis in research and EBM. ${ }^{18}$ To resolve this, evidence based guidelines with a welldocumented pool of instructions for EBM practice need to be created by physicians with good knowledge of literature search and statistical interpretation of medical evidence. Ironically, there are limited resources to create and maintain such guidelines due to which physicians need to find answers to their clinical questions that may arise during their clinical practice by accessing original researches and other medical literature. This further emphasizes the need to develop skills to critically appraise the research question, study design and mode of research conduct, and biostatistical analysis of every study to appropriately interpret the results. ${ }^{24}$

Many faculty are relatively unaware that Evidence based medicine [EBM] may be important for improved teaching and do not integrate them into their teaching. EBM emphasizes the focus on epidemiological principles rather than the teaching of statistical methods. Statistical contribution in medical research has proven that it sheds additional light and clarity 
when used judiciously and appropriately. On the other hand, there is a risk of it being misused if results or conclusions of the studies are lacking merit. Both descriptive and inferential statistics are frequently used in dental publications. These authors depend on statisticians who may be professional but are lacking the knowledge of dentistry. In such circumstances, there may be confusions in concluding the statistical data. ${ }^{6}$

The understanding of the biostatistics subject and its application in research is of utmost importance. The inadequate knowledge may be perceived as Biostatistics to be a difficult subject, lack of understanding of its importance, inadequate learning in the curriculum with no desire to learn the subject, inability to foresee its need in evidence based approach and applications. Incorporation of problem based learning into biostatistics courses can be quite helpful as possible solutions to the limitations in teaching biostatistics are identified by the respondents of the study. The curriculum should include a student centered approach encouraging good interaction and emphasizing on the use of biostatistics. For dental students with little prior knowledge encountering statistics for the first time, it is important that they encounter it in the context that they will be using it during their subsequent research careers. Problem based learning is the need of the hour which can cause a shift from conventional didactic learning experience to a more practical based approach.

\section{CONCLUSIONS}

Biostatistics plays a central role in planning, conducting, analyzing the results and reporting of important data. Hence, a better understanding of biostatistics is necessary for clinicians as well as academicians. The faculty are mostly aware of the importance of biostatistics in research, however the level of comprehension and application needs to be addressed and improved to a higher level.

Data sharing statement provided by the authors is available with the full text of this article at jemds.com.

Financial or other competing interests: None.

Disclosure forms provided by the authors are available with the full text of this article at jemds.com.

\section{REFERENCES}

[1] Pocock SJ, Collier TJ, Dandreo KJ, et al. Issues in the reporting of epidemiological studies: a survey of recent practice. BMJ 2004;329(7471):883.

[2] Hinton RJ, Dechow PC, Abdellatif $\mathrm{H}$, et al. Creating an evidence-based dentistry culture at baylor college of dentistry: the winds of change. J Dent Edu 2011;75(3):279-90.

[3] Greenhalgh T. How to read a paper. Statistics for the nonstatistician. I: different types of data need different statistical tests. BMJ 1997;315(7104):364-6.

[4] Ahmadi-Abhari S, Soltani A, Hosseinpanah F. Knowledge and attitudes of trainee physicians regarding evidencebased medicine: a questionnaire survey in Tehran, Iran. J Eval Clin Pract 2008;14(5):775-9.
[5] Mullner M, Matthews H, Altman DG. Reporting on statistical methods to adjust for confounding: a crosssectional survey. Ann Intern Med 2002;136(2):122-6.

[6] Batra M, Gupta M, Dany SS, et al. Perception of dental professionals towards biostatistics. Int Sch Res Not 2014;2014:291807.

[7] Sayed I, Abdul S. Effect of a course of biostatistics in an integrated curriculum. J Med Diagn Meth 2018;7(1):268.

[8] Sujatha BK, Reddy MN, Vijayan S. Assessment of knowledge, attitude and perception about biostatistics among faculty and postgraduate students in a dental institution, Bengaluru City-a cross-sectional survey. J Dent Res Rev 2018;5(2):54-8.

[9] Altman DG, Bland JM. Improving doctors' understanding of statistics. J R Statist Soc A 1991;154(2):223-67.

[10] Feingold A. Cognitive gender differences are disappearing. American Psychologist 1988;43(2):95-103.

[11] Lindberg SM, Hyde JS, Petersen JL, et al. New trends in gender and mathematics performance: a meta-analysis. Psychol Boll 2010;136(6):1123-35.

[12] Windish DM, Huot SJ, Green ML. Medicine residents' understanding of the biostatistics and results in the medical literature. JAMA 2007;298(9):1010-22.

[13] Hannigan A, Hegarty AC, Mcgrath D. Attitudes towards statistics of graduate entry medical students: the role of prior learning experiences. BMC Med Educ 2014;14(1):70.

[14] Kumar L, Shahnawaz K, Choudhary S, et al. Attitudes toward biostatistics among post-graduate medical students in Kishanganj, Bihar. Journal of Evolution of Medical and Dental Sciences 2014;3(3):758-62.

[15] Bourzgui F, Abidine Z, Diouny S, et al. Assessment of knowledge, perception regarding biostatistics and interpretation of research among moroccan dental professionals. International Journal of Dentistry Research 2019;4(2):49-54.

[16] Gezmu M, DeGruttola V, Dixon D, et al. Strengthening biostatistics resources in sub-Saharan Africa: research collaborations through US partnerships. Stat Med 2011;30(7):695-708.

[17] AlShareef MH. Satisfaction of family physicians during their training program, Jeddah, Saudi Arabia. Int J Med Sci Pub Health 2014;3(6):649-60.

[18] Javali S, Sunkad MA. Awareness and attitude towards applications of biostatistics by the healthcare professionals in their decision making in north Karnataka, India. J Biostat Epidemiol 2016;2(2):76-80.

[19] Manja V, Lakshminrusimha S. Principles of use of biostatistics in research. Neoreviews 2014;15(4):e13350.

[20] Johnston BC, Alonso-Coello P, Friedrich JO, et al. Do clinicians understand the size of treatment effects? A randomized survey across 8 countries. CMAJ 2016;188(1):25-32.

[21] Al-Zahrani SH, Al-Khail BA. Resident physician's knowledge and attitudes toward biostatistics and research methods concepts. Saudi Med J 2015;36(10):1236-40.

[22] Baghi H, Kornides ML. Current and future health care professionals attitudes toward and knowledge of statistics: how confidence influences learning. J Nurs Educ Pract 2013;3(7):24-9. 
[23] Novack L, Jotkowitz A, Knyazer B, et al. Evidence-based medicine: assessment of knowledge of basic epidemiological and research methods among medical doctors. Postgrad Med J 2006;82(974):817-22.
[24] Miettunen J, Nieminen P, Isohanni M. Statistical methodology in general psychiatric journals. Nord J Psychiatry 2002;56(3):223-8. 